\title{
Validity of Immunofluorescence Test for the Detection of Respiratory Viruses Causing Acute Lower Respiratory Tract Infection Among Under Five Children
}

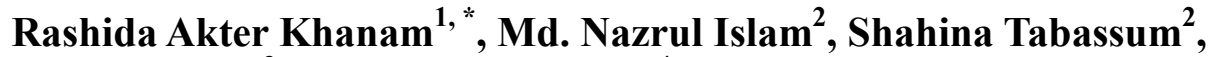 \\ Ahmed Sharif $^{3}$, Md. Abdullah Yusuf ${ }^{4}$ \\ ${ }^{1}$ Department of Microbiology, Shaheed Suhrawardy Medical College, Dhaka, Bangladesh \\ ${ }^{2}$ Department of Virology, Banghabandhu Sheikh Mujib Medical University, Dhaka, Bangladesh \\ ${ }^{3}$ Department of ENT, Mugda Medical College, Dhaka, Bangladesh \\ ${ }^{4}$ Department of Microbiology, National Institute of Neurosciences \& Hospital, Dhaka, Bangladesh
}

\section{Email address:}

rafsancosmo@gmail.com (R. A. Khanam), profnazrul@yahoo.com (Md. N. Islam),

shahina.tabassum@yahoo.com (S. Tabassum), entsharif@gmail.com (A. Sharif), ayusuf75@yahoo.com (Md. A. Yusuf)

${ }^{*}$ Corresponding author

\section{To cite this article:}

Rashida Akter Khanam, Md. Nazrul Islam, Shahina Tabassum, Ahmed Sharif, Md. Abdullah Yusuf. Validity of Immunofluorescence Test for the Detection of Respiratory Viruses Causing Acute Lower Respiratory Tract Infection Among Under Five Children. Advances in Materials. Vol. 3, No. 1, 2018, pp. 7-10. doi: 10.11648/j.ijmb.20180301.12

Received: January 6, 2018; Accepted: February 1, 2018; Published: March 2, 2018

\begin{abstract}
Background: Respiratory viruses cause a variety of human infections, ranging from the common cold to lifethreatening pneumonia. Over 200 strains of virus can cause respiratory disease. The majority of severe viral respiratory infections are caused by relatively few viruses, primarily parainfluenza virus types 1,2 and 3, respiratory syncytial virus (RSV), influenza A and B viruses, and adenovirus. Objective: The purpose of this study was to see the validity of Immunofluorescence test for the detection of Respiratory viruses causing acute lower respiratory tract infection among under five children. Methodology: This cross sectional study was conducted in the Department of Virology at Bangabandhu Sheikh Mujib Medical University, Dhaka from July 2002 to June 2003 for a period of one year. The children with the age group of below five (5) years presented with the clinical manifestations of acute lower respiratory tract infection (ALRI) who were visited or were admitted to Dhaka Medical College Hospital (DMCH), Dhaka were selected as study population. Nasopharyngeal aspirates were collected. Viruses were detected by cell line culture and direct Immunoflorescence (DFA) method. Result: The study was carried out among 100 children aged from new born to 60 months with acute lower respiratory tract infection (ALRI). Highest rate (85.7\%) of isolation was obtained among children between 0 to 24 months of age. There was a significant reduction in the number of cases in older children in 25 to 60 months of age group. The most common virus isolated from the under five children was respiratory syncytial virus which was 20(95.2\%). Adenovirus was isolated in only $1(4.8 \%)$ case. No other viruses were found in this study. DFA method typically more rapid than the cell culture and also detect virus which has lost viability in transit. Culture methods on the other hand, are more favorable for detecting low titer of viable virus. In this study 17 samples are positive by cell culture and these are also positive by DFA. Total 21 samples are positive by DFA and among them 4 samples are negative. Conclusion: DFA is highly sensitive and specific for detection of respiratory viruses among the under-five children. Furthermore the accuracy of this test is also very high. Therefore it is recommended that the DFA test can be used for the detection of respiratory virus from the children presented with respiratory tract infection.
\end{abstract}

Keywords: Respiratory Viruses, Acute Lower Respiratory Tract Infection, Under Five Children, Cell Culture, Immunoflourescence, Test Validity 


\section{Introduction}

Acute respiratory tract infections are the leading cause of death among children throughout the world. An estimated 6.5 million children below 5 years of age die each year due to acute respiratory tract infections [1]. The majority of deaths due to respiratory tract infections are caused by acute lower respiratory tract infection (ALRI) [2]. It has been estimated that four million children in developing countries die each year from pneumonia [3]. In rural areas of Bangladesh, a child below 5 years experiences two to three episodes of ALRI each year. ALRI is also the principal cause of hospitalization among children in both urban and rural areas [4].

Respiratory viruses cause a variety of human infections, ranging from the common cold to life-threatening pneumonia. Over 200 strains of virus can cause respiratory disease [5]. The majority of severe viral respiratory infections are caused by relatively few viruses, primarily parainfluenza virus types 1, 2 and 3, respiratory syncytial virus (RSV), influenza $A$ and $B$ viruses, and adenovirus [6].

Cell culture method is sensitive and can detect a broad spectrum of viruses [7]. Numerous rapid antigen detection systems are also very sensitive and specific and available for the diagnosis of respiratory viruses [8]. The purpose of the present study was to see the comparison between immunoflorescence and cell line culture of viruses causing acute lower respiratory tract infection among fewer than five children.

\section{Methodology}

This cross-sectional study was conducted in the Department of Virology at Bangabandhu Sheikh Mujib Medical University (BSMMU), Dhaka form July 2002 to June 2003 for a period of one (01) year. Children with both sexes with the age group of fewer than 5 years of age presented with the clinical manifestations of acute lower respiratory tract infection (ALRI) who were visited or were admitted to Dhaka Medical College Hospital (DMCH), Dhaka were enrolled in the study. Informed verbal consent was taken from the parents. Detailed history was recorded in a preformed questionnaire. Nasopharyngeal aspirates were collected from the pediatric in-patient and outpatient department of Dhaka Medical College Hospital (DMCH) Dhaka, Bangladesh. The laboratory works were performed in the department of Virology at BSMMU and the cell line culture of respiratory viruses were performed in the Institute of Public Health (IPH), Mohakhali, Dhaka. Children accepted for this study were $<5$ years old and had symptoms of cough and one or more of the following: Respiratory rate more than 50/min, chest retraction, wheezing, stridor, cyanosis, rales, fever, inability to feed, history of illness less than 7 days. Isolation of respiratory viruses was performed by inoculation of specimen in HEp-2 cell line and identification of respiratory viruses by direct fluorescence antibody technique. The numerical data obtained from the study were analyzed and significance of difference was estimated by using the statistical methods. Data were expressed in percentage as applicable. Comparison between groups was done by Chi -square test. Probability less than 0.05 was considered as significant.

\section{Results}

The study was carried out among 100 children aged from new born to 60 months with acute lower respiratory tract infection (ALRI). Highest rate $(85.7 \%)$ of isolation was obtained among children between 0 to 24 months of age. There was a significant reduction in the number of cases in older children in 25 to 60 months of age group. Difference between the rate of isolation of respiratory viruses in the 0 to 24 months age group and that in age group 25 to 60 months was significant $(\mathrm{P}<0.05)$. Viral infection was more common in 0 to 24 months of age group (Table 1 ).

Table 1. Distribution of Infected Children with Respiratory Viruses According to Their Age Group $(n=100)$.

\begin{tabular}{lllll}
\hline \multirow{2}{*}{ Age } & \multicolumn{2}{l}{ Virus detection } & \multirow{2}{*}{ Total } & P \\
\cline { 2 - 3 } & Positive & Negative & & value \\
\hline 0 to 24 months & $18(85.7 \%)$ & $60(75.9 \%)$ & $78(78 \%)$ & \\
25 to 60 months & $3(14.3 \%)$ & $19(24.1 \%)$ & $22(22 \%)$ & \\
Total & $21(100 \%)$ & $79(100 \%)$ & $100(100 \%)$ & \\
\hline
\end{tabular}

*Chi-square test was performed corrected by Fisher's Exact Test.

The most common virus was respiratory syncytial virus $20(95.2 \%)$ isolated from the under five children. Adenovirus was isolated in only $1(4.8 \%)$ case. No other viruses were found in this study (table 2).

Table 2. Distribution of Virus According To Clinical Manifestation ( $n=21)$.

\begin{tabular}{lll}
\hline Virus Name & Frequency & Percentage \\
\hline RSV & 20 & 95.2 \\
Influenza virus & 0 & 0.0 \\
Parainfluenza virus & 0 & 0.0 \\
Adenovirus & 1 & 4.8 \\
Total & $\mathbf{2 1}$ & $\mathbf{1 0 0 . 0}$ \\
\hline
\end{tabular}

A total of 21 samples were positive by Immunofluorescence and viruses were isolated from 17 $(17 \%)$ of the 100 patients (Table 3 ).

Table 3. Shows the frequency of different viruses which were isolated by cell culture method and by Immunofluorescence from nasopharyngeal aspirate.

\begin{tabular}{llll}
\hline \multirow{2}{*}{ DFA } & \multicolumn{2}{l}{ Cell Line Culture } & \multirow{2}{*}{ Total } \\
\cline { 2 - 3 } & Positive & Negative & \\
\hline Positive & $17(100.0 \%)$ & $4(4.82 \%)$ & $21(21 \%)$ \\
Negative & $0(0.0 \%)$ & $79(95.18 \%)$ & $79(79 \%)$ \\
Total & $17(100.0 \%)$ & $83(100.0 \%)$ & $100(100.0 \%)$ \\
\hline
\end{tabular}

The sensitivity, specificity, positive predictive value (PPV), negative predictive value (NPV) and accuracy were $100.0 \%, 95.2 \%, 80.9 \%$ (95\% CI 60 to $92.33 \%), 100.0 \%$ (95\% CI 95.4 to $100.0 \%$ ) and $96.0 \%$ respectively. 
Table 4. Diagnostic Validity of the DFA test.

\begin{tabular}{lll}
\hline Values & Value & $\mathbf{9 5 \%}$ CI \\
\hline Sensitivity & $100.0 \%$ & 80.49 to $100.00 \%$ \\
Specificity & $95.2 \%$ & 88.12 to $98.67 \%$ \\
PPV & $80.9 \%$ & 60 to $92.33 \%$ \\
NPV & $100.0 \%$ & 95.4 to $100.0 \%$ \\
Accuracy & $96.0 \%$ & 90.07 to $98.90 \%$ \\
\hline
\end{tabular}

positive predictive value $=\mathrm{PPV}$; negative predictive value $=\mathrm{NPV}$

\section{Discussion}

Viral respiratory tract infections are the most common diseases affecting humans throughout the world. More than 5 million children under the age of 5 years experience lower respiratory infections. Respiratory syncytial virus (RSV), influenza $\mathrm{A}$ and $\mathrm{B}$ viruses and human parainfluenza virus (HPIV) type 1, 2 and 3 cause about 80.0 to $90.0 \%$ of viral LRIs [10]. Respiratory syncytial virus (RSV) is a leading cause of acute lower respiratory tract infections in infants and young children and is responsible for nearly $50 \%$ of all bronchiolitis and $25.0 \%$ of all pneumonia cases during early months of life. It occurs at a frequency of more than four times compared to other respiratory viruses [11].

In the current study of 100 children of less than 5 years old, $78 \%$ were in 0 to 24 months age group. Viral infection was more common in this group than 25 to 60 months. Thus among the 78 patients in this age group of (0 to 24 months) respiratory viruses were detected about 18 (23.07\%) while respiratory viruses were detected only in $3(13.63 \%)$ of 22 children who were aged 25 to 60 months. Similar observation was been reported by Huq et al [1]. They reported that the rates of viral shedding in children aged 0 to 24 months and 25 to 60 months was $24.5 \%$ and $12.5 \%$ respectively.

In the present study, respiratory viruses were detected by Immunofluorescent test in $21 \%$ out of 100 patients under 5 years age. A comparable rate of detection of respiratory viruses was reported from a study conducted in New Haven, USA, where respiratory viruses were detected in 367(23.97\%) out of 1531 children with LRTI11. Ruutu et al [9] reported 51.9\% prevalence of respiratory virus in Filipino children. Respiratory syncytial virus is the most frequent agent of acute lower respiratory tract disease in young infants19. In the present study RSV was responsible for highest number of viral infections. Thus, among the total 21 respiratory isolated viruses, RSV was detected in $20(95.23 \%)$ cases. Similar finding was reported by Huq et al [1] from a study conducted in Dhaka where they have detected 103(78\%) RSV among the total 132 isolated respiratory viruses. Hijazi et al [12] also detected $168(73 \%)$ RSV among the total 230 respiratory viruses isolated from children with LRTI from a study in Kuwait. There were some studies of conducted among children in a number of countries had shown a rate of detection of respiratory virus ranged from 19 to $51.9 \%$. Forgie et al [13] reported $19 \%$ prevalence of respiratory virus in rural children in Gambia. John et al [14] reported 49\% prevalence of respiratory virus in Southern India and Shann et al [15] reported $29.0 \%$ prevalence from a study in children in New
Guinea. In the present study the rate of respiratory virus isolation from children of acute respiratory tract infection was $21.0 \%$. Thus it was evident that prevalence found in the present study was also within the range of prevalence from these studies. This study included only children who were brought to the hospital, the sample biased toward more severe cases of ALRI and was not representative of all cases in the community. The most important outcome of this study was the detection of viruses in children with ALRI.

Viral disease diagnosis has traditionally relied on the isolation of viral pathogens in cell cultures. Although this approach is often slow and requires considerable technical expertise, it has been regarded for decades as the gold standard for the laboratory diagnosis of viral disease [16]. Cell culture studies provide a valuable complement to in vivo experiments, allowing for a more controlled manipulation of cellular functions and processes. For decades, cell lines have played a critical role in scientific advancements, yet researchers have become increasingly cautious when interpreting data generated from cell lines only [17].

Immunofluorescence a method of determining the location of antigen or antibody in a tissue section or smear using a specific antibody or antigen labeled with a Flurochrome [16]. There are two major types of immunofluorescence techniques, both based on the antigen - antibody reaction in which the antibody attaches itself to a specific antigen. In the direct fluorescent antibody (DFA) method, the antibody coats the antigen and cannot be easily removed by washing. The antibody remains attached to the cell after all non-antibody globulin has been washed away. The antibody has been rendered fluorescent by conjugation with fluorescein or another dye. In indirect fluorescent antibody (IFA) method, the specific antibody is allowed to react with the antigen. The non-antibody globulin is then washed off. This is then treated with a labeled antibody to the specific antibody. Fluorescent antibody studies have been used in the detection of numerous bacterial, viral, fungal, and protozoan infections and in the identification of many microscopic tissue constituents [18].

DFA method typically more rapid than the cell culture and also detect virus which has lost viability in transit [19]. Culture methods on the other hand, are more favorable for detecting low titer of viable virus. In this study 17 samples are positive by cell culture and these are also positive by DFA. Total 21 samples are positive by DFA and among them 4 samples are negative. True positive cases are 21 and false positive are 4 in number. In this study false negative is $0(0.0 \%)$ and total negative are 79 in number. Therefore total positive are 21 and total negative are 79 in number.

Data were extracted to construct two-by-two tables, which were used to calculate the sensitivity and specificity of the rapid DFA tests. In this study sensitivity $100.0 \%$, specificity $95.2 \%$, and accuracy $96.0 \%$. Another study was done in Columbus and they compared with culture with DFA kit and had a sensitivity and specificity of $73.0 \%$ and $92.0 \%$ respectively [20]. 


\section{Conclusion}

In conclusion the DFA is highly sensitive and specific for detection of respiratory viruses among the under-five children. Furthermore the accuracy of this test is also very high. Therefore it is recommended that the DFA test can be used for the detection of respiratory virus from the children presented with respiratory tract infection.

\section{Funding Agency}

There was no funding agency involved in this research.

\section{Conflict of Interest}

There was no conflict of interest to any of the authors.

\section{References}

[1] Rahman M, Huq F, Sack DA, Butler T, Azad AK, Alam A, Nahar N, Islam M. Acute lower respiratory tract infections in hospitalized patients with diarrhea in Dhaka, Bangladesh. Rev Infect Dis 1990;12:899-906.

[2] Nair H, Simoes EA, Rudan I, Gessner BD, AzzizBaumgartner E, Zhang JS, Feikin DR, Mackenzie GA, Moiisi JC, Roca A, Baggett HC. The global and regional burden of hospital admissions for severe acute lower respiratory infections in young children in 2010: a systematic analysis. Lancet 2013; 381 (9875): 1380-90.

[3] Mazur NI, Martinon-Torres F, Baraldi E, Fauroux B, Greenough A, Heikkinen T, Manzoni P, Mejias A, Nair H, Papadopoulos NG, Polack FP. Lower respiratory tract infection caused by the respiratory syncytial virus: current management and new therapeutics. Lancet Respiratory Med 2015; 3 (11): 888-900.

[4] Nasreen S, Luby SP, Brooks WA, Homaira N, Al Mamun A, Bhuiyan MU, Rahman M, Ahmed D, Abedin J, Rahman M, Alamgir AS. Population-based incidence of severe acuterespiratory virus infections among children aged $<5$ years in rural Bangladesh, June-October 2010. PloS one 2014; 9 (2): e89978.

[5] Halstead DC, Todd S, Fritch G. Evaluation of five methods for respiratory syncytial virus detection. J Clin Microbiol 1990; 28: $1021-1025$.

[6] Chattopadhyay D, Chatterjee R, Anand VK, Kumari S, Patwari AK. Lower respiratory tract infection in hospitalized children due to the respiratory syncytial (RS) virus during a suspected epidemic period of RS virus in Delhi. J Trop Paediatr 1992; 38; 68-73.

[7] Rudan I, Boschi-Pinto C, Biloglav Z, Mulholland K, Campbell H. Epidemiology and etiology of childhood pneumonia. Bulletin World Health Organization 2008; 86: 408-416.

[8] Landry ML, Ferguson D. SimulFluor respiratory screen specimens by immunofluorescence staining for rapid detection of multiple respiratory viruses in clinical specimen. J Clin Microbiol 2000; 35: 708-711.

[9] Ruutu P, Halonen P, Meurman O, Torres C, Paladin F, Yamaoka K, Tupasi FE. Viral lower respiratory tract infections in Filipino children. J Infect Dis 1990; 161: I75-179.

[10] Fan J, Henrickson KJ, Savatski LL. Rapid simultaneous diagnosis of infections with respiratory syncytial viruses A and $\mathrm{B}$, influenza viruses $\mathrm{A}$ and $\mathrm{B}$, human parainfluenza virus types 1,2 , and 3 by multiplex quantitative reverse transcription-polymerase chain reaction -enzyme hybridization assay (Hexaplex). Clin Infect Dis 1998; 26: 1397-1402.

[11] Maitreyi RS, Kabra SK, Ghosh M, Dar L, Seth P, Prasad AK. Rapid detection methods for diagnosis of acute lower respiratory tract infections in young children due to respiratory syncytial virus. Indian J Med Microbiol 1999; 17(1):10.

[12] Hijazi Z, Pacsa A. Gharbawy FE, Chugh Essa TDS, Shazli $\mathrm{AE}$, Salam RAE. Acute lower respiratory tract infections in children in Kuwait. Ann of Trop Paediatr 1997;17:127-134.

[13] Forgie IM, PHD, Campbell H, Evans NL, Leinonen M, Neil KPO, Saikku P, Whittle HC, Greenwood BM. Etiology of acute lower respiratory tract infections in children in a rural community in the Gambia. Pediatr Infect DisJ 1992; 11: 44673.

[14] John TJ, Cherian T, Steinhoff MC, Simoes EAF, John M. Etiology of acute respiratory infections in children in tropical southern India. Rev Infect Dis 1991; 13: 463-9.

[15] Shann F, Germer S, Hazlett D, Gratten M, Linnemann V, Payne R. Etiology of pneumonia in children in Goroka hospital, Papua New Guinea. Lancet 1984;8: 537-41.

[16] Diane S. Leland and Christino C Ginocchio American Society of Microbiology.

[17] Guerrier G, Goyette S, Chheng ET, Rampart B, Brand L, Te V, Try PL, Sarah R, Cavailler P, Mayaud C, Guillard B. Acute viral lower respiratory tract infections in Cambodian children:clinical and epidemiologic characteristics. Pediatric Infect Dis J 2013; 32 (1): e8-13.

[18] Feng L, Li Z, Zhao S, Nair H, Lai S, Xu W, Li M, Wu J, Ren L, Liu W, Yuan Z. Viral etiologies of hospitalized acute lower respiratory infection patients in China, 2009-2013. PloS one 2014; 9 (6): e99419.

[19] Hacimustafaoglu M, Celebi S, Bozdemir SE, Ozgur T, Ozcan İ, Guray A, Cakir D. RSV frequency in children below 2 years hospitalized for lower respiratory tract infections. Turkish J Pediatric 2013; 55 (2): 130.

[20] Hughes JH, Mann DR, Hamparian VV. Detection of respiratory syncytial virus in clinical specimens by viral culture, direct and indirect immunofluorescence, and enzyme immunoassay. Department of Medical Microbiology and Immunology, College of Medicine, Ohio State University, Columbus 43210 . 